\title{
REVIEW
}

\section{RNA-Binding Proteins in Female Reproductive Pathologies}

Kasra Khalaj, ${ }^{*}$ Jessica E. Miller, ${ }^{*}$ Christian R. Fenn, ${ }^{*}$ SooHyun Ahn, ${ }^{*}$ Rayana L. Luna, ${ }^{\dagger}$ Lindsey Symons, ${ }^{*}$ Stephany P. Monsanto, * Madhuri Koti, ${ }^{*}$ and Chandrakant Tayade*

From the Department of Biomedical and Molecular Sciences, * Queen's University, Kingston, Ontario, Canada; and the Ultrastructure Laboratory, ${ }^{\dagger}$ Aggeu Magalhães Research Center of the Oswaldo Cruz Foundation, Recife, Brazil

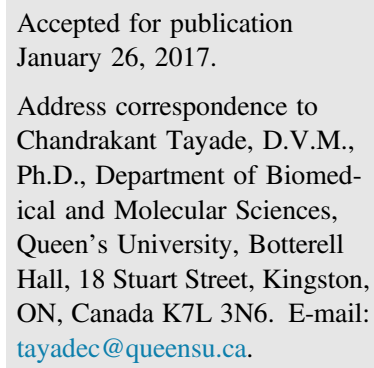

\begin{abstract}
RNA-binding proteins are key regulatory molecules involved primarily in post-transcriptional gene regulation of RNAs. Post-transcriptional gene regulation is critical for adequate cellular growth and survival. Recent reports have shown key interactions between these RNA-binding proteins and other regulatory elements, such as miRNAs and long noncoding RNAs, either enhancing or diminishing their response to RNA stabilization. Many RNA-binding proteins have been reported to play a functional role in mediation of cytokines involved in inflammation and immune dysfunction, and some have been classified as global post-transcriptional regulators of inflammation. The ubiquitous expression of RNAbinding proteins in a wide variety of cell types and their unique mechanisms of degradative action provide evidence that they are involved in reproductive tract pathologies. Aberrant inflammation and immune dysfunction are major contributors to the pathogenesis and disease pathophysiology of many reproductive pathologies, including ovarian and endometrial cancers in the female reproductive tract. Herein, we discuss various RNA-binding proteins and their unique contributions to female reproductive pathologies with a focus on those mediated by aberrant inflammation and immune dysfunction. (Am J Pathol 2017, 187: 1200-1210; http://dx.doi.org/10.1016/j.ajpath.2017.01.017)
\end{abstract}

Post-transcriptional gene regulation (PTGR) is an imperative process for the overall health of eukaryotic cells and mRNAs. With recent advancements in sequencing and proteomics screening techniques, >1500 RNA-binding proteins (RNABPs) have been identified to interact with all classes of RNAs. ${ }^{1}$ These RNABPs form ribonucleoprotein complexes with RNAs and proteins, which are crucial units involved in gene regulation. ${ }^{2}$ Most RNABPs are ubiquitously expressed in higher than average levels compared to other proteins. ${ }^{1}$ Post-transcriptional regulation of mRNA has a downstream function in various signaling pathways. ${ }^{3}$ Many RNABPs have diverse binding specificity and have been reported to interact with RNAs encoding for functionally relevant genes. ${ }^{4}$ Similar to miRNAs, many of these RNABPs coordinate regulation of related mRNAs. ${ }^{5-7}$ Mutations, which result in aberrant expression or functioning of these RNABPs, highlight the importance of these regulatory molecules in many processes central to adequate cellular health, including their contribution to pathologies.
Next-generation sequencing and other advanced profiling techniques and biochemical methods, such as photoactivatable ribonucleoside-enhanced cross-linking and immunoprecipitation, have revealed the abundance and diversity of RNABPs and their interactions with multiple RNA subclasses. ${ }^{8}$ The classification of RNABPs by their interacting RNA targets has allowed for the isolation of specific PTGR pathways involved in human diseases. Although much of the published research on RNABPs has focused on mRNA binding proteins, there are other RNABPs that play a role in PTGR through their interaction with noncoding RNAs (ncRNAs). ${ }^{1}$ These ncRNAs may become encoded into ribonucleoprotein complexes, and therefore serve as guides to direct the ribonucleoprotein complexes to search out target transcripts and genome loci. ${ }^{9}$

\footnotetext{
Supported by the Canadian Institutes of Health Research grant 394924 (C.T.).

Disclosures: None declared.
} 
Gerstberger et $\mathrm{al}^{1}$ elegantly generated a census of human RNABPs analyzed for their interactions with different classes of RNA and characterized 122 RNABPs that interact with ncRNAs, including miRNAs, P-element induced wimpy testis (PIWI)-interacting RNAs, and long noncoding RNAs. These ncRNAs, along with their corresponding RNABPs, can control multiple aspects of post-transcriptional mRNA processing via degradation, silencing, or activation of gene loci. For example, miRNAs repress mRNA stability through their association with Argonaute proteins, ${ }^{10}$ whereas PIWIinteracting RNAs protect the genome from genomic instability by interacting with PIWI proteins. ${ }^{9}$ Thus, the relationship between these ncRNAs, RNABPs, and their respective PTGR pathways provides a greater dimension of complexity when analyzing the role of RNABPs in disease pathologies.

In the female reproductive tract, inflammation is part of the ovulation process and normal endometrial tissue remodeling during menstruation. Inflammation is also necessary for embryo implantation and downstream events in a successful pregnancy. ${ }^{11}$ Simply put, these processes are tightly regulated by coordinated actions of cytokines, chemokines, decoy receptors, and immune cell networks. These inflammatory mediators are influenced by female sex hormones, estrogen and progesterone. ${ }^{12}$ Inflammation has also been implicated in most reproductive pathologies. ${ }^{12,13} \mathrm{Un}$ controlled, delayed, or dysregulated delicate homeostatic inflammatory processes have all been demonstrated to contribute to disease pathogenesis in the reproductive tract, including endometriosis and pregnancy loss. ${ }^{11,14}$

Herein, we present an overview of RNABPs that interact with RNAs or other post-transcriptional regulators in the context of inflammation-mediated female reproductive pathologies. We focus on the function of these RNABPs as well as their mechanisms in cancer and non-cancer reproductive pathologies. For the purpose of this review, we will restrict contributions of RNABPs to the pathophysiology of endometriosis, endometrial and ovarian cancer, and pregnancy loss.

\section{Overview of Post-Transcriptional Gene Regulation Mechanisms}

The formation of a type of ribonucleoprotein complex, the RNA-induced silencing complex, is required for miRNAmediated gene silencing. ${ }^{15}$ The miRNA-induced silencing complex is composed of miRNAs, which are directly bound by members of the Argonaute protein family. ${ }^{16}$ The association of miRNA-induced silencing complex with an mRNA via base pairing allows for the mediation of both mRNA decay and translational repression through the recruitment of various enzyme complexes. ${ }^{15,17}$ Deadenylases are first recruited, followed by cytoplasmic mRNA degradation in the $3^{\prime}-5^{\prime}$ or $5^{\prime}-3^{\prime}$ direction by the RNA exosome or exoribonuclease 1 , respectively. ${ }^{18,19}$ Many proteins involved in the $5^{\prime}-3^{\prime}$ mRNA degradation pathway concentrate in granular cytoplasmic foci known as processing bodies, which have also been shown to colocalize with various miRNA-mediated RNA decay factors. ${ }^{17,18}$ The export of the mRNAs from the nucleus to the cytoplasm is a necessary process for the aforementioned degradation pathway mechanisms to successfully occur. Some RNABPs, such as the Tristetraprolin (TTP; ZFP36) family, exhibit autoregulatory negative feedback loops via binding to their own regulatory elements, such as $3^{\prime}$ untranslated regions, and cause degradation of their own mRNA. ${ }^{20,21}$ P-body assembly is dependent on the pool of mRNA to be decayed and is induced in response to stresses or other conditions that lead to the inhibition of translation initiation. ${ }^{22}$ In addition, stress granules are cytoplasmic structures that also form during certain types of cellular stress. ${ }^{17}$ Translationally repressed mRNAs aggregate within these stress granules, which are then sorted and delivered to processing bodies for degradation. ${ }^{18}$ Both processing bodies and stress granules contain various shared components, including mRNA, eukaryotic translation initiation factor $4 \mathrm{E}$, microribonucleoproteins, and regulators of mRNA stability and translation such as RNABPs. ${ }^{23}$ Thus, processing bodies and stress granules are dynamic structures that have been reported to play a critical role via the interplay between RNABPs, mRNA decay, and translation.

\section{Modulation of Immune-Inflammation Axis by RNABPs}

RNABPs and their role in reproductive pathologies is an emerging field. It has been shown that RNABPs regulate inflammation and immune cell functions, and as a result are implicated in inflammation-associated pathologies. In this review, we have summarized the role of RNABP in inflammation and immune cell modulation because a delicate balance between inflammatory mediators and sex hormones is key to successful female reproductive events. ${ }^{24}$ The role of RNABPs in inflammation and immune cell biology has been highlighted in the context of selected reproductive pathologies.

\section{Modulation of Inflammation by HuR/TTP Axis RNABPs}

Given that most of the previous investigations on inflammation modulation by RNABPs have been focused on the human antigen-R (HuR)/TTP axis, this review will primarily highlight this axis. ${ }^{25,26}$ Recently, TTP has been classified as a global post-transcriptional regulator of feedback control in inflammation. ${ }^{27}$ Both HuR and TTP are expressed in the nucleus and cytoplasm of a wide variety of cell types of the reproductive tract, including innate immune cells, such as macrophages. TTP activation is dependent on p38-activated MAP kinaseactivated protein kinase- 2 phosphorylation at the site of serine 52 and 178 in the mouse ${ }^{28}$ and 60 and 186 in humans by extracellular signal regulated kinase 2 protein kinase. ${ }^{29}$ 
Phosphorylation of TTP allows preferential binding of 14-3-3protein in the cytoplasm. The formation of this complex renders TTP ineffective as a destabilizing protein as it leads to the reduction of TTP affinity to AU-rich elements (AREs) on inflammatory cytokine transcripts. ${ }^{28,30,31}$ Conversely, some in vitro studies have demonstrated that phosphorylation has no impact on ARE-binding-mediated degradation by TTP. ${ }^{32}$ Phosphorylation status of TTP also has been reported to be associated with CCR4-Not1 deadenylation complex and HuR/ TTP MAP kinase-activated protein kinase-2 phosphorylation modulation of ARE-dependent translation. ${ }^{31}$ Non 14-33 -bound TTP can bind to the $3^{\prime}$ untranslated region AREs of inflammatory cytokines, such as tumor necrosis factor
$\alpha(\mathrm{TNF}-\alpha)$ and mediate degradation via $5^{\prime}-3^{\prime}$ and $3^{\prime}-5^{\prime}$ pathways aforementioned above (Figure 1).

Taylor et $\mathrm{al}^{33}$ documented that TTP-deficient mice generated by targeted disruption of $Z f p 36$ gene, although normal at birth, developed systemic autoinflammatory phenotype within 1 to 8 weeks after birth. The hyperinflammatory phenotype was primarily attributed to elevated circulating levels of TNF- $\alpha$ as injection of neutralizing TNF$\alpha$ antibodies reversed the inflammatory phenotype in TTPdeficient mice. Additional studies in TTP-deficient mice led to the identification of granulocyte-macrophage colonystimulating factor as another physiological target of TTP. ${ }^{25}$ Furthermore, TTP expression is correlated with severity of

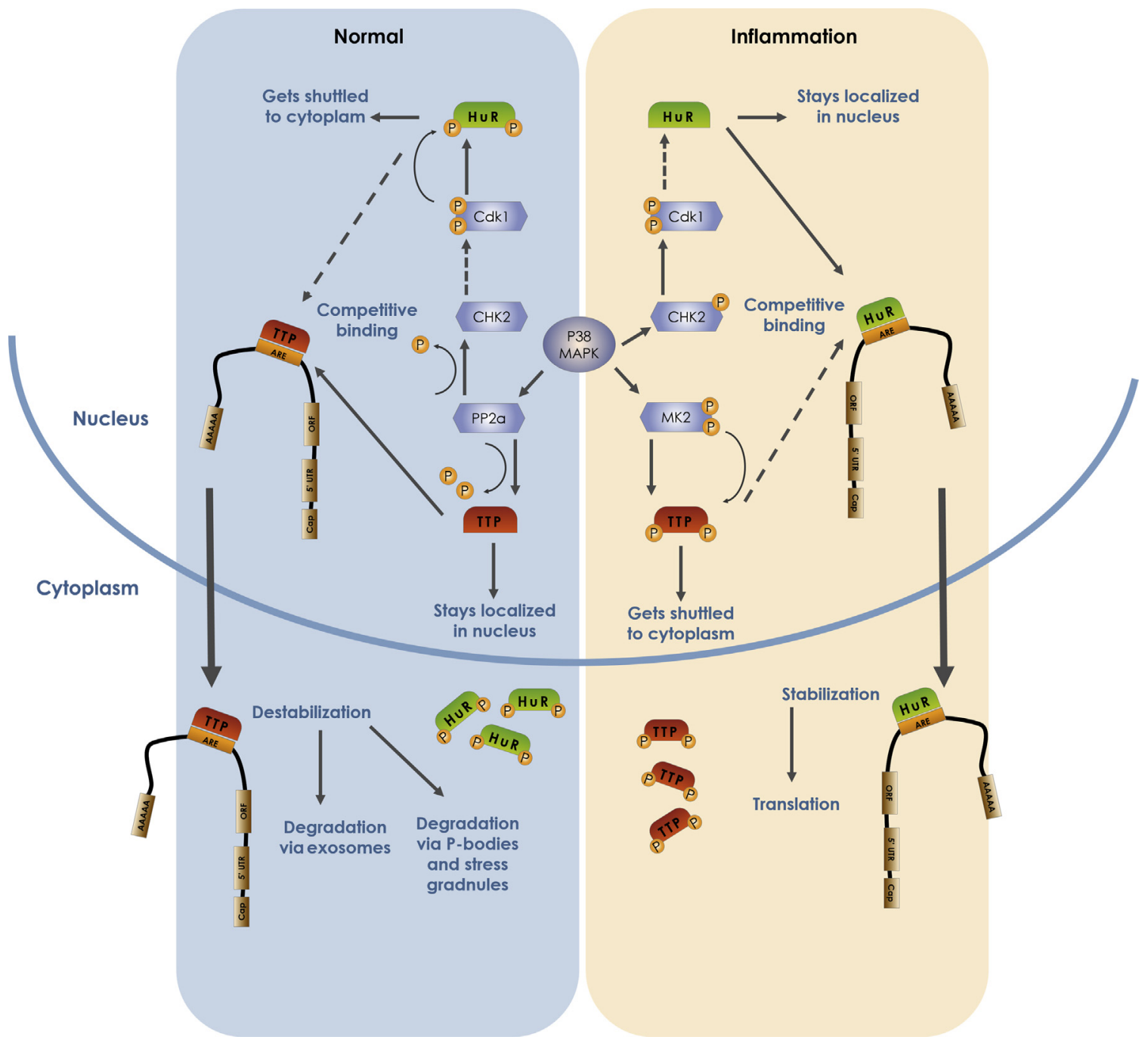

Figure 1 Modulation of inflammation by the HuR/TTP axis. The balance between HuR and TTP is shifted in response to external stress stimuli. Under normal conditions (left), P38 activates protein phosphatase 2a (PP2a), which catalyzes the dephosphorylation and activation of TTP. At the same time, PP2a deactivates serine/threonine protein kinase Chk2 (Chk2), which allows cyclin-dependent kinase 1 (Cdk1) to phosphorylate HuR and render it inactive. Phosphorylated HuR can be translocated to the cytoplasm, tipping the balance in favor of TTP, which can bind the mRNAs of inflammatory cytokines and promote their degradation. Under stress conditions (right), P38 activates mitogen-activated protein kinase-activated protein kinase 2 (MK2), which phosphorylates and deactivates TTP and allows it to be translocated to the cytoplasm. At the same time, P38 activates Chk2, which can phosphorylate and deactivate Cdk1. The inhibition of Cdk1 allows HuR to remain dephosphorylated, which adds to the transport of TTP out of the nucleus, tips the balance in favor of HuR, which can bind the mRNAs of inflammatory cytokines and stabilize them to promote their translation, thus promoting the inflammatory response. There are numerous additional players in this pathway that help maintain this balance. Dashed arrow indicates inhibited binding. AAAAA, poly A tail; ARE, AU rich element; ORF, open reading frame; $\mathrm{P}$, phosphorylation; P-bodies, processing bodies. 
rheumatoid arthritis, ulcerative colitis, and systemic lupus erythematosus in humans. ${ }^{26}$ On the other side of the axis, HuR can bind to most of the same cytokines possessing AREs, such as TNF- $\alpha$, and stabilize the transcripts. Much like TTP, HuR nucleocytoplasmic shuttling and activation are in part dependent on p38 mitogen-activated protein kinase-mediated phosphorylation, ${ }^{34}$ and phosphorylation by checkpoint kinase $2,{ }^{35}$ protein kinase $\mathrm{C},{ }^{36}$ and cyclindependent kinase 1 can influence binding activity of HuR on inflammatory mRNAs. ${ }^{37}$ Because NF- $\mathrm{KB}$ controls many cytokines involved in inflammation, it is not surprising that the TTP/HuR axis is involved in regulation of several NF- $\kappa B$ signaling-dependent proinflammatory cytokines. Tiedje et $\mathrm{al}^{27}$ have elegantly demonstrated that a phosphorylationdependent inactivation of TTP is required for NF- $\kappa \mathrm{B}$ signal transduction. In addition, TTP can impair NF- $\kappa \mathrm{B} / \mathrm{p} 65$ nuclear translocation in an ARE-mediated decay-independent manner and can ultimately result in TTP-induced cell death. ${ }^{27,38}$ These data clearly suggest that the HuR/TTP axis is a critical regulator of physiological inflammation, and any perturbations in this axis will potentially lead to autoimmune and inflammatory conditions.

A high number of RNABPs expressed in the reproductive tract regulate the expression of genes encoding inflammatory molecules, either promoting or controlling inflammation. ${ }^{39}$ For example, roquin- $1,{ }^{40}$ regnase- $1,{ }^{41}$ and tristetraprolin ${ }^{27}$ are RNABPs that attenuate inflammatory responses via target mRNA degradation, whereas HuR is often suggested to oppose TTP, thereby promoting inflammation through target mRNA stabilization. ${ }^{42}$ Mice with germline knockout of TTP display a severe inflammatory phenotype with myeloid hyperplasia and autoimmunity due to excessive TNF production, indicating the role of TTP in the regulation of TNF transcript expression. ${ }^{43}$ Conversely, the role of HuR in PTGR has been less straightforward. Although HuR participates in the transcript stabilization and expression of proinflammatory cytokine IL-17 in a mouse model of experimental autoimmune encephalomyelitis, it can also act as a negative regulator of macrophage-mediated inflammation. ${ }^{44}$ Overexpression of HuR was shown to act as a translational silencer for TNF, IL-1 $\beta$, and transforming growth factor- $\beta 1$, whereby the production of these proteins was decreased after lipopolysaccharide (LPS) challenge in mice compared to controls that did not overexpress HuR. ${ }^{45}$ Some studies have linked interactions between HuR and miRNAs via shared mRNA functional binding sites. ${ }^{46}$ Indeed, competitive miRNAs, such as miR-637, have been reported to also vie for binding of inflammatory molecules. ${ }^{47}$

\section{Modulation of Immune Cell Development by RNABPs}

In nonpathological conditions, immune cell populations are dynamic and differentiate normally. ${ }^{48}$ RNABPs participate in the development and differentiation of lymphoid cells, such as $\mathrm{T}$ and $\mathrm{B}$ cells. In particular, conditional double knockout of ZFP36L1 and ZFP36L2 in lymphocytes lead to the development of T-lymphoblastic leukemia in double- knockout mice, whereas single knockout of either gene displays no developmental defect, indicating a unique multiRNABP pathogenesis-dependent role in lymphocytes. ${ }^{49}$ The development of T-lymphoblastic leukemia is attributed to the increased production of Notch homolog 1 (Notch1), elucidating a novel transcript target for ZFP36L1 and ZFP36L2 and the importance of both RNABPs in the developmental regulation of $\mathrm{T}$ lymphocytes in the thymus. ${ }^{49}$ The RNABP HuR is also involved in the developmental programming of both $\mathrm{T}$ and $\mathrm{B}$ cells. Conditional knockout of HuR in thymocytes elucidates its role in thymopoesis as a cell cycle suppressor and modulator of proapoptotic signals. ${ }^{50} \mathrm{In}$ B cells, the production of HuR protein is up-regulated threefold on stimulation with LPS or with anti-CD40 and IL-4 and IL-5 in vitro compared to unstimulated B cells. ${ }^{51}$ Furthermore, B-cell-specific conditional knockout of HuR leads to significantly lower production of all types of immunoglobulin isotypes in the serum of mice, except for IgA when compared to control mouse, indicating that HuR is necessary for antibody production after antigenic challenge. ${ }^{51}$

The RNABPs TIA1 cytotoxic granule associated RNA binding protein (TIA-1) cytotoxic granule-associated RNABP and TTP prevent pathological overexpression of TNF- $\alpha$ via inhibition of translation by TIA- 1 and degradation of TNF- $\alpha$ transcripts by TTP. Deletion of TIA-1 in mice results in mild arthritis, whereas deletion of TTP results in severe arthritis, as well as cachexia, dermatitis, and autoantibody formation. ${ }^{33}$ Mice containing deletions in both TIA-1 and TTP develop severe arthritis. ${ }^{52}$ RNABP experiments investigating immunomodulation by RNABPs indicate that TIA-1/TTP knockout murine macrophages secrete lower TNF- $\alpha$ protein when stimulated by LPS, indicative that these RNABPs are not only involved in PTGR, but can alter cell variation, which can further exasperate inflammatory pathologies. ${ }^{52}$

\section{The Importance and Contributions of Gene Regulation by RNABPs in Reproduction and Associated Pathologies}

Although the roles of many RNABPs are commonly focused on inflammatory pathways, RNABPs also appear to have a significant role in the initiation and regulation of normal reproductive events. In the female reproductive tract specifically, a number of RNABPs are involved in reproductive events, including but not limited to oocyte maturation, ovulation, endometrial tissue remodeling, embryo implantation, placenta development, and successful pregnancy. We have provided a summary of RNABP contributions in female reproductive pathologies in Figure 2.

\section{RNABPs in Embryonic Growth and Placental Development}

RNABPs, including ZFP36/TTP as well as its less-studied family members, ZFP36L1 (Tis11b), ZFP36L2 (Tis11d), and 


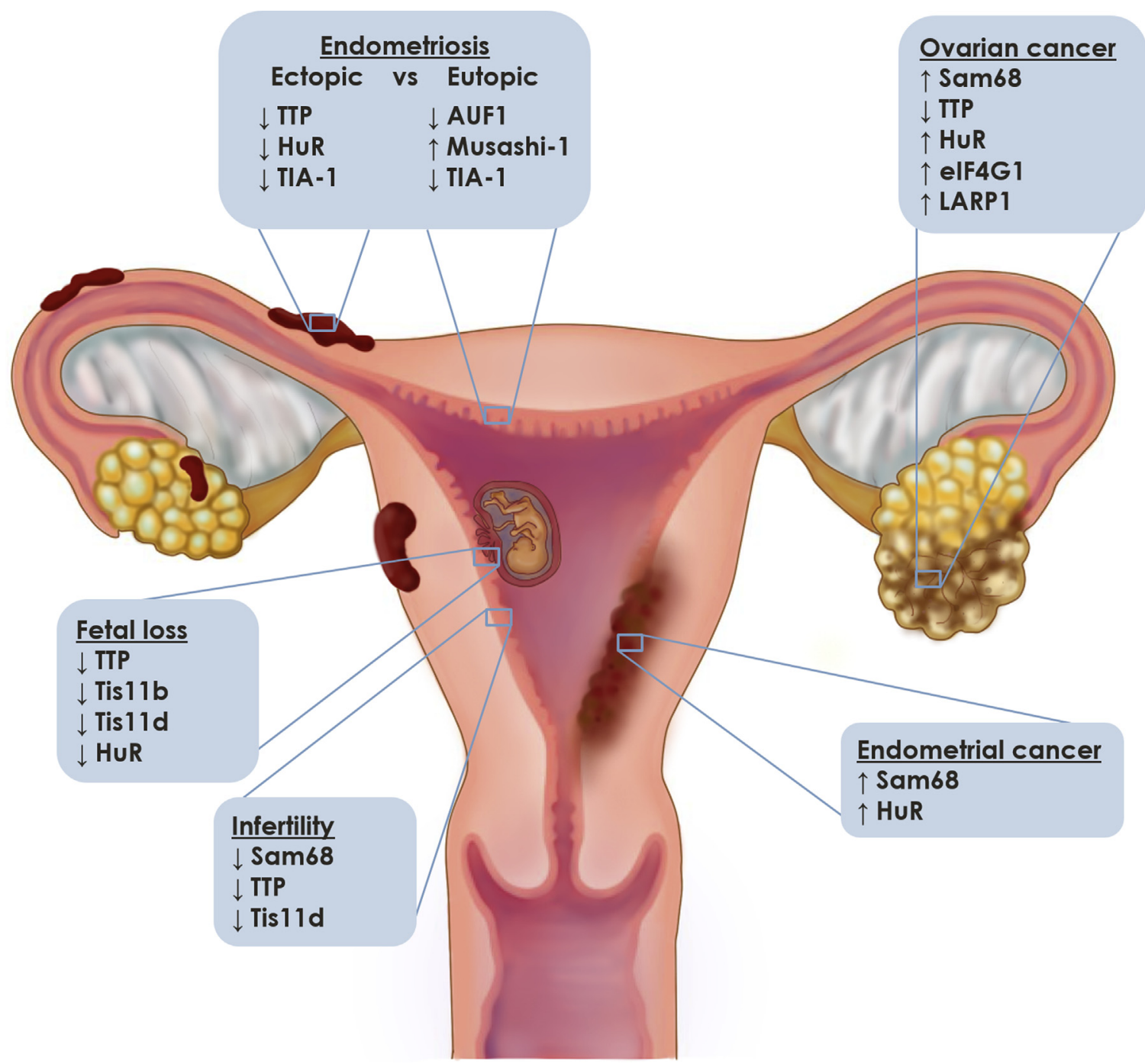

Figure 2 Contributions of RNA-binding proteins (RNABPs) in female reproductive pathologies. The dysregulation of the immune inflammation axis in endometriosis, fetal loss, infertility, and ovarian and endometrial cancer, is mediated in part by RNABPs, which have been shown to be differentially regulated in animal models as well as humans. AUF1, AU-rich element-binding factor 1; eIF4G1, eukaryotic translation initiation factor $4 \gamma 1$; TIA-1, TIA1 cytotoxic granule associated RNA binding protein.

the rodent-specific ZFP36L3, are readily detectable in placental tissues and yolk sac in humans and in mice. ${ }^{53,54}$ Indeed, we found differential expression of TTP family members in a first-trimester human trophoblast cell line, HTR-8/SVNeo between normoxic and hypoxic conditions, suggesting an abundance of TTP family members in placenta and their potential regulation under hypoxia (K.K., C.T., unpublished data). In fact, RAW264.7 macrophages stimulated with potent inflammatory trigger lipopolysaccharide, under prolonged hypoxic conditions, led to reduced TNF- $\alpha$ protein levels. This decrease in TNF- $\alpha$ was mediated by TTP-dependent destabilization of TNF- $\alpha$ mRNA via a $3^{\prime}$-untranslated region-dependent mechanism, suggesting a regulatory role for TTP in hypoxia-dependent resolution of inflammation. ${ }^{55}$ Using a knockout mouse model of rodentspecific ZFP36L3, a number of growth factors, including heparin-binding epidermal growth factor, endothelial lipase Lipg, and type 1 transferrin receptor, which is responsible for iron uptake by the placenta for the developing fetus, were shown to be likely targets of ZFP36L3 ${ }^{54}$ In addition, ZFP6L2 has been shown to be critical for female fertility because of the crucial role of RNABPs in early embryonic development. The amino-terminal truncated form of ZFP36L2 causes arrest in early embryonic development at the two-cell stage. Disruption of the ZFP36L1 gene in mice results in an embryonic lethal phenotype at the embryonic day 11 because of disruptions in chorioallantoic fusion. ${ }^{56}$ Recent evidence suggests that HuR/embryonic lethal, abnormal vision-like 1 (ELAVL1) elicits transcriptional and post-transcriptional changes in mRNAs important for extraembryonic (placental and yolk sac) as well as embryonic development. ${ }^{57}$ Using ELAVL1 knockout mice (embryonic lethal), the initiation of branching and processes of labyrinth morphogenesis, which are imperative for placental development, are absent from the knockout model, suggesting HuR/ELAVL1 is involved in this initiation of branching. ${ }^{57}$ 
RNABPs in Ovulation, Oocyte Maturation, and Female Fertility

RNABP mRNAs are expressed in the reproductive tract of humans and mice and are influenced by menstrual/estrous cycles. ${ }^{58,59}$ Female mice with mutations in ZFP36L2 were unable to ovulate even under pharmacological conditions, and attempts to mature oocytes from these mice ex vivo was hindered because of meiotic arrest imposed by cAMP. ${ }^{60}$ Using the TTP knockout mouse model, it has also been demonstrated that TTP is critically involved in mouse meiosis, chromosomal arrangement, spindle morphology, and polar body extrusion, all of which are critical events for oocyte maturation. ${ }^{61}$ Meiotic asymmetry and a lack of oocyte polarization significantly decreases reproductive success in females and likely contributes to infertility. ${ }^{62}$ Furthermore, ablation of the Src associated in mitosis of $68 \mathrm{kDa}$ (Sam68) RNABP induces sterility and infertility in females because of its essential role in oocyte maturation and its involvement in the expression of gonadotropin receptors in the ovary. ${ }^{63}$ These data clearly provide evidence that disruptions in RNABPs impede female fertility.

\section{Post-Transcriptional mRNA Regulation by RNABPs in Endometriosis and Pregnancy Loss}

Endometriosis, a proinflammatory gynecological disease, is characterized by the growth of the endometrial-like tissue outside of uterine cavity. Research to understand the immunological basis behind disease establishment has elucidated aberrant inflammation and immune system dysfunction in endometriosis patients. ${ }^{64}$ The innate arm of the immune system, such as macrophages, is polarized toward the M2 phenotype, which specializes in tissue repair, instead of tissue clearance via phagocytosis. ${ }^{65}$ In addition, increased concentration of inflammatory cytokines in the biological fluids from patients further strengthens the notion of the involvement of immune system in the development of endometriosis. ${ }^{66}$ Inflammatory cytokines have also been directly implicated to initiate symptoms of pain and infertility in endometriosis patients. ${ }^{67,68}$ Aberrant activation of RNABPs may participate in this process via PTGR of transcripts encoding for proinflammatory cytokines.

Recent work from our group has indicated dysregulation of the HuR/TTP axis in patient ectopic lesions compared to matched eutopic endometrium obtained from women with endometriosis (K.K., S.H.A., M. Bidarimath, Y. Nasirzadeh, S.S. Singh, A.T. Fazleabas, S.L. Young, B.A. Lessey, M.K., C.T., unpublished data). In addition, we have demonstrated differential responses of inflammatory cytokines in endometriotic and epithelial endometrial cell lines, suggesting a potential functional role of the HuR/TTP axis in the pathophysiology of endometriosis. Women with endometriosis present decreased TIA-1 and HuR expression, both of which are RNABPs responsible for modulation of proinflammatory cytokines, in the eutopic and ectopic endometrium compared to normal healthy controls. ${ }^{59,69}$ Decreases in regulatory molecules of inflammation likely contribute to the pathogenesis and pathophysiology of endometriosis by contributing to the inflammatory milieu in the peritoneal cavity and symptoms of pain and infertility observed in endometriosis patients. Another RNABP that has been implicated in the pathogenesis of endometriosis is Musashi-1. ${ }^{70}$ This stem cell marker is frequently associated with tumorigenesis and abnormal growth; however, it has also been found to be elevated in the eutopic endometrium of endometriosis patients. ${ }^{70}$ Finally, the RNABP heterogeneous nuclear ribonucleoprotein D0, AUF-1, which mediates the destabilization of the mRNA of DNA methyltransferase 1 , is lower in the eutopic endometrium of endometriosis patients. ${ }^{71}$ Together, correlative evidence of these RNABPs shows promise and points toward involvement via inflammation and immune-modulatory pathogenesis mechanisms. However, many additional studies are required to understand the molecular mechanism of RNABP contributing to the pathogenesis of endometriosis.

Recurrent pregnancy loss (RPL) is a multifactorial disorder for patients who experience pregnancy failure in the first trimester more than two or three times. ${ }^{72}$ Aberrant maternal inflammation has been linked with thrombosis during fetal loss, and fetal distress molecular pathways influence fetal health outcome. Our group has demonstrated that the TTP family may be involved in spontaneous fetal loss in a porcine model of pregnancy loss. ${ }^{73}$ Currently, there are no reports on the direct involvement of RNABPs with recurrent pregnancy loss in humans, but given their presence at the maternal-fetal interface and regulation of several key inflammatory processes, it is logical to assume that RNABPs potentially participate in the pathogenesis of RPL. We have recently shown that TTP and HuR RNABPs are expressed in the placenta, and TTP is involved in the modulation of inflammation-induced RPL via aberrant expression in an LPS-induced mouse model of RPL. ${ }^{74}$ In addition, our group has demonstrated differential localization patterns of TTP in placentas obtained from LPS-treated mice. ${ }^{74}$ Collectively, we believe that these RNABPs are participating in pathogenesis of pregnancy loss, including RPL via aberrant nucleocytoplasmic localization shuttling and expression.

Overall, it is apparent that a dysregulation of RNABP contributes to increases in reproductive tract inflammation and immune dysfunction and ultimately contributes to pathogenesis of reproductive pathologies. However, the role of RNABP across different cell types of the female reproductive pathologies is not well characterized and requires further investigation to understand the molecular mechanisms underlying the relationship between RNABP and specific reproductive pathologies.

\section{Gene Regulatory Mechanisms and RNABPs Implicated in Endometrial and Ovarian Cancer}

RNABPs play important roles in RNA regulation in tumor carcinogenesis and development. Recent research has gone 
into unraveling RNABP involvement in cancers, including endometrial and ovarian cancer. Although many studies have been correlative and have focused on clinical outcomes and normal tissue compared to carcinoma expression levels, increasingly literature is starting to unveil unique mechanistic interactions between RNABPs and other regulatory factors during cancer development and transformation. Epithelial ovarian cancer is the most deadly gynecological disease, ${ }^{75}$ with a median survival of 2 to 4 years. ${ }^{76}$ Endometrial carcinoma is the most common gynecological malignancy worldwide, and in recent decades the incidence of endometrial carcinoma has been increasing. ${ }^{77}$

Sam68 is a KH domain RNABP involved in a wide range of cellular processes, including signal transduction, transcription, RNA metabolism, cell cycle progression, and apoptosis. ${ }^{78,79}$ Sam68 features six proline-dominated sequences and a tyrosine-rich area at its $\mathrm{C}$ terminus. ${ }^{78}$ Signaling proteins that include $\mathrm{SH} 2$ or $\mathrm{SH} 3$ domains bind at these important regions. ${ }^{78}$ The activity of Sam68 may be altered via tyrosine hydroxylase, which interrupts homodimerization, leading to reduced affinity for RNA in vitro. ${ }^{80}$ This RNABP has been associated with poor prognostic roles in a wide variety of cancers, including non-small-cell lung cancer, ${ }^{81}$ bladder cancer, ${ }^{82}$ esophageal squamous cell carcinoma, ${ }^{83}$ colorectal cancer, ${ }^{84}$ and aggressive neuroblastoma ${ }^{85}$ Expression of Sam68 at both the mRNA and protein levels in both epithelial ovarian cancer ${ }^{79}$ and endometrial carcinoma is significantly higher in pathological tissue when compared to para-tumor tissue and normal tissue. ${ }^{86}$ The elevated expression of Sam68 in endometrial cancer is also significantly associated with histological grade, International Federation of Gynecology and Obstetrics stage, and myometrial invasion. ${ }^{86}$ Sam68 has a proliferative effect on tissues, as demonstrated via siRNA knockdown experiments of this gene in both human endometrial adenocarcinoma (Ishikawa) ${ }^{86}$ and epithelial ovarian cancer (OVCAR-3) cells. ${ }^{79}$ Furthermore, random homozygous knockout-induced Sam68 deficiencies in nude mice lead to tumor-suppressing effects and increased metastatic tumors. ${ }^{87}$ It has also been suggested that its role is dependent on a range of factors, including context and type of tissue ${ }^{88}$ Determining the biological mechanisms of Sam68 could be valuable as we potentially progress to viewing Sam68 in a therapeutic sense.

In addition to noncancer reproductive pathologies, HuR has been extensively studied with regard to its roles in a variety of cancers, including epithelial ovarian cancers. ${ }^{89}$ In the cytoplasm, HuR stabilizes mRNA, aiding to translation of its bound transcripts, and may act as a tumor maintenance gene. ${ }^{90} \mathrm{HuR}$ has been shown to be involved in proliferation, apoptosis, angiogenesis, metastasis, invasion, and chemotherapy resistance, ${ }^{89}$ all of which are tightly linked to cancer pathology. In addition to being involved in inflammation regulation covered earlier, HuR regulates many mRNAs that are hallmarks of cancer progression, such as p53, vascular endothelial growth factor, cyclins, and cyclooxygenase $2 .{ }^{91}$ Furthermore, HuR expression is significantly increased in both poorly differentiated and advanced stage endometrial carcinomas. $^{91}$ Indeed, knockdown of HuR results in decreased cell proliferation and induction of apoptosis in in vitro models using Ishikawa cells. ${ }^{90}$ In an investigation of HuR associated with ovarian cancer, HuR was found to be present in the nucleus in most cases. ${ }^{92}$ This nuclear HuR was significantly linked with invasive and high-grade cancers as well as poor disease-free survival. ${ }^{92}$ Nuclear HuR intensity, through multivariate analysis, was demonstrated to be an independent prognostic factor for poor disease-free survival. ${ }^{92}$ Together, these data point toward altered phosphorylation status of HuR, resulting in potentially higher inactive HuR that likely contributes to aberrant inflammation in endometrial carcinomas.

Evidence of complex miRNA-RNABP networks has been reported in ovarian cancer pathogenesis. HuR has also been implicated in ovarian cancer by stabilizing long noncoding RNAs, which contribute to its pathogenesis. ${ }^{93}$ NEAT1, a long noncoding RNA, is up-regulated in ovarian cancer, both within cell lines and patient samples, and HuR has been reported to preserve NEAT1's structural integrity. ${ }^{93}$ Specifically in metastatic high-grade serous ovarian carcinomas, HuR mRNA and protein levels are widely expressed and mRNA levels are connected to poor survival outcomes in high-grade serous ovarian carcinoma patients. ${ }^{91}$

La-related protein 1 (LARP1) is an evolutionarily conserved RNABP, and has been associated with many cancers. ${ }^{94}$ LARP1 knock-down studies have revealed that LARP1 is necessary for both cancer cell survival and chemotherapy resistance. ${ }^{94}$ In vivo, this RNABP incites tumor formation. ${ }^{94}$ It increases the amount of available mRNA of genes involved in cell survival, including B-cell lymphoma 2, human epidermal growth factor receptor 3 , and Rac- $\gamma$ serine/threonine-protein kinase, and reduces the amount of available proapoptotic genes, such as BIK, TNFA, and $D A P K 2 .{ }^{94}$ It is pertinent to note that within ovarian cancer patients, the tumor's response to chemotherapy is a vital determinant of survival, which makes LARP1 particularly relevant in this kind of cancer. ${ }^{94}$ This notion is strengthened by the fact that patients with the highest LARP1 mRNA expression have reported significantly worse outcomes, and a heightened risk of death at any time. ${ }^{94}$ RNABP eukaryotic translation initiation factor $4 \gamma 1$ is a subunit of the eukaryotic translation initiation complex, and it aids in ensuring the establishment of the mRNAribosome by recruiting mRNA to the ribosome. ${ }^{95}$ This is a critical process, as the formation of this complex is the ratelimiting step of the initiation stage of mRNA translation. ${ }^{95}$ The expression of eukaryotic translation initiation factor 4 $\gamma 1$ in serous ovarian cancer at both the mRNA and protein level is significantly up-regulated and associated with clinical tumor stage. ${ }^{95}$ In addition, patients with low eukaryotic translation initiation factor $4 \gamma 1$ protein reported longer survival time. ${ }^{95}$ Together, findings of these key RNABPs outline the clinicopathological relevance of these RNABPs in reproductive cancers. 
In addition to dysregulated RNABP expression, aberrant miRNA expression has also been demonstrated in ovarian cancer pathogenesis. ${ }^{96,97}$ Direct connections with miRNAs and RNABPs have been reported with respect to the Drosha and DGCR8 core components in miRNA biogenesis microprocessor, because RNABPs can confer specificity for recruiting and processing different pri-miRNAs. ${ }^{98}$ It has been shown that RNA binding molecules p68, ${ }^{99}$ p $72,{ }^{99}$ KSRP, ${ }^{100}$ and TAR DNA-binding protein $43^{101}$ all can specifically modulate miRNA maturation via interactions with the miRNA processing complexes. RNABP human DEAD-box protein has been demonstrated to be a regulatory modulator of miRNAs involved in DNA damage via its modulatory effects on the Drosha processing of a select group of miRNAs. ${ }^{102}$ Inhibition of this RNABP results in ovarian tumor growth and metastasis in mice and poor clinical outcomes in human patients with serous ovarian cancer. ${ }^{102}$ In addition, RNABPs Lin28B and insulin-like growth factor 2 have been shown to be correlated in ovarian cancer. ${ }^{103}$ Although much progress has been made to determine this association between miRNAs and RNABPs in cancer, further studies will need to further elucidate links between their cancer-specific interactions and cancer progression. Moving forward, research in this field may be crucial in finding molecular targets for selected therapies, determining prognosis, and addressing chemoresistance.

\section{RNABPs as Potential Therapeutic Targets}

Because of their ubiquity, RNABPs at the clinical level have not been used for biomarker detection. Currently, preclinical trials using compounds that attenuate or up-regulate RNABPs have yielded promising findings. Nanotherapybased drug delivery approaches have become a feasible type of treatment of cancers in the past few years and most recently have been shown to be useful for dermatologicrelated pathologies. ${ }^{104}$ Moreover, nanoparticles have been used in carrying DNA fragments and RNA inhibitors, such as siRNA, and these options may change the future of treating pathologies. ${ }^{104}$ The improvement in our understanding of HuR has led to novel therapeutic exploration. Cy-3-labeled folic acid-derivatized DNA dendrimer nanocarriers are used as a targeted delivery system of siRNAs. These nanocarriers contain siRNAs for HuR and have already been demonstrated to be successful in suppressing tumor growth in mice with ovarian cancer and significantly increasing their lifespan. ${ }^{105}$ In addition, HuR nanotherapy in combination with a CXCR4 antagonist has been reported to control lung cancer metastasis via suppression of CXCR4stromal cell-derived factor 1 axis. ${ }^{106}$ These encouraging results support the continuation of research in this specific field of targeted cancer therapies. However, similar to all mRNA regulators, including miRNAs, specificity to both the gene of interest and site of the targeted biological pose challenges. Indeed, the need to understand the roles of RNABPs in different cell populations has been previously highlighted. ${ }^{105,107}$ Furthermore, long-term benefits of RNABP biologics have not been evaluated and could also prove to be limiting, especially because of the fact that these are protein-based therapeutics and will likely not be able to be delivered as oral biologics. RNABPs such as the HuR/ TTP axis, which primarily target inflammatory cytokines, are early to intermediate responders; thus, targeting this axis may not translate to long-term biologics. Another important aspect to take into consideration is that potential nonspecificity is minimized as nanoparticles can be specifically delivered to the target tissue or organ. In a pharmacological sense, early to intermediate elements usually result in homeostatic changes in the patient short-term, but over time, the homeostatic changes can revert because of other mechanisms, such as miRNA families with the same inflammatory targets being up-regulated in response to downregulation induced by biologics. When taken together, it comes as no surprise then that RNABPs have been identified as therapeutic targets to treat inflammatory diseases; however, additional research is required to validate the feasibility of this new type of treatment using nanotechnology.

Since the first anti-TNF biological therapy was authorized by the US Federal Drug Administration, current TNF inhibitors have shown efficacy in dampening inflammation. These drugs are mainly either monoclonal antibodies or fusion proteins that confer the characteristic of being injectable and disintegrate when digested. Indeed, many other therapeutic targets have been developed since, including anti-IL-23, IL-1, IL-6, and interferons, among others, to treat a wide variety of inflammatory pathologies, such as rheumatoid arthritis, psoriasis, multiple sclerosis, and pediatric autoimmune disorders. ${ }^{108}$ However, modulation of inflammatory response is one of the many key points to address severe immunosuppression as well as serious adverse events. Because of these reasons, these therapeutics have a limited safety profile and patients are monitored carefully. ${ }^{107}$ Despite the success of biological therapies worldwide, there are still some unmet needs regarding the treatment of immune- and inflammation-mediated disorders. Nevertheless, TTP overexpression in the mouse model has demonstrated the capability to protect mice from autoimmune disorders, which suggest the benefit of a drug that simulates TTP may be a good agent to treat inflammationmediated pathologies, including reproductive tract pathologies. ${ }^{109}$

\section{Conclusions}

In this review, we highlighted the importance of RNABPs and their contributions to reproductive pathologies. We also sought to highlight unique mechanisms, with an emphasis on the HuR/TTP axis, that these RNABPs influence their 
target genes to exert their effects in a wide variety of cell types as well as potential use as therapeutic targets. Their unique involvement with $\mathrm{NF}-\kappa \mathrm{B}$ in regulation of inflammation, cell senescence, and proliferation further highlights their importance in maintaining a homeostatic balance. Furthermore, unique cancer-specific functions of some RNABPs may be at play in endometrial and ovarian cancer. We believe that, although the reproductive field lacks knowledge on RNABPs compared to other molecules involved in PTGR such as miRNAs, RNABPs contribute to these pathologies as much as miRNA networks. Because of the intricate roles of RNABPs in maintaining homeostasis, we believe that rather than evaluating RNABP families in separation, they should be investigated as a ratio. Future investigations should evaluate the unique interplays between PTGR mechanisms shared or in tandem with RNABPs and other regulators as well as the unique roles of RNABPs on translation, success, or failure of the targets, and their unique contributions to reproductive tract pathologies.

\section{References}

1. Gerstberger S, Hafner M, Tuschl T: A census of human RNA-binding proteins. Nat Rev Genet 2014, 15:829-845

2. Piñol-Roma S, Choi YD, Matunis MJ, Dreyfuss G: Immunopurification of heterogeneous nuclear ribonucleoprotein particles reveals an assortment of RNA-binding proteins. Genes Dev 1988, 2:215-227

3. Dibrov A, Kashour T, Amara FM: The role of transforming growth factor beta signaling in messenger RNA stability. Growth Factors 2006, 24:1-11

4. Hogan DJ, Riordan DP, Gerber AP, Herschlag D, Brown PO: Diverse RNA-binding proteins interact with functionally related sets of RNAs, suggesting an extensive regulatory system. PLoS Biol 2008, 6:e255

5. Keene JD: RNA regulons: coordination of post-transcriptional events. Nat Rev Genet 2007, 8:533-543

6. Lukong KE, Chang KW, Khandjian EW, Richard S: RNA-binding proteins in human genetic disease. Trends Genet 2008, 24:416-425

7. Blanchette M, Green RE, MacArthur S, Brooks AN, Brenner SE, Eisen MB, Rio DC: Genome-wide analysis of alternative pre-mRNA splicing and RNA-binding specificities of the Drosophila hnRNP A/B family members. Mol Cell 2009, 33:438-449

8. Hafner M, Landthaler M, Burger L, Khorshid M, Hausser J, Berninger $\mathrm{P}$, Rothballer A, Ascano $\mathrm{M}$ Jr, Jungkamp AC, Munschauer M, Ulrich A, Wardle GS, Dewell S, Zavolan M, Tuschl T: Transcriptome-wide identification of RNA-binding protein and microRNA target sites by PAR-CLIP. Cell 2010, 141:129-141

9. Clark JP, Lau NC: Piwi proteins and piRNAs step onto the systems biology stage. Adv Exp Med Biol 2014, 825:159-197

10. Lu YC, Chang SH, Hafner M, Li X, Tuschl T, Elemento O, Hla T: ELAVL1 modulates transcriptome-wide miRNA binding in murine macrophages. Cell Rep 2014, 9:2330-2343

11. Comba C, Bastu E, Dural O, Yasa C, Keskin G, Ozsurmeli M, Buyru F, Serdaroglu H: Role of inflammatory mediators in patients with recurrent pregnancy loss. Fertil Steril 2015, 104:1467-1474.e1

12. Jabbour HN, Sales KJ, Catalano RD, Norman JE: Inflammatory pathways in female reproductive health and disease. Reproduction 2009, 138:903-919

13. Weiss G, Goldsmith LT, Taylor RN, Bellet D, Taylor HS: Inflammation in reproductive disorders. Reprod Sci 2009, 16:216-229
14. Kwak-Kim J, Yang KM, Gilman-Sachs A: Recurrent pregnancy loss: a disease of inflammation and coagulation. J Obstet Gynaecol Res 2009, 35:609-622

15. Iwakawa HO, Tomari Y: The functions of microRNAs: mRNA decay and translational repression. Trends Cell Biol 2015, 25:651-665

16. Wilczynska A, Bushell M: The complexity of miRNA-mediated repression. Cell Death Differ 2015, 22:22-33

17. Wu X, Brewer G: The regulation of mRNA stability in mammalian cells: 2.0. Gene 2012, 500:10-21

18. Garneau NL, Wilusz J, Wilusz CJ: The highways and byways of mRNA decay. Nat Rev Mol Cell Biol 2007, 8:113-126

19. Schmid M, Jensen TH: The exosome: a multipurpose RNA-decay machine. Trends Biochem Sci 2008, 33:501-510

20. Brooks SA, Connolly JE, Rigby WFC: The role of mRNA turnover in the regulation of tristetraprolin expression: evidence for an extracellular signal-regulated kinase-specific, AU-rich element-dependent, autoregulatory pathway. J Immunol 2004, 172:7263-7271

21. Tchen CR, Brook M, Saklatvala J, Clark AR: The stability of tristetraprolin mRNA is regulated by mitogen-activated protein kinase p38 and by tristetraprolin itself. J Biol Chem 2004, 279:32393-32400

22. Decker CJ, Parker R: P-bodies and stress granules: possible roles in the control of translation and mRNA degradation. Cold Spring Harb Perspect Biol 2012, 4:a012286

23. Kedersha N, Anderson P: Mammalian stress granules and processing bodies. Methods Enzymol 2007, 431:61-81

24. Miller JE, Ahn SH, Monsanto SP, Khalaj K, Koti M, Tayade C: Implications of immune dysfunction on endometriosis associated infertility. Oncotarget 2016, 8:7138-7147

25. Carballo E, Lai WS, Blackshear PJ: Evidence that tristetraprolin is a physiological regulator of granulocyte-macrophage colony-stimulating factor messenger RNA deadenylation and stability. Blood 2000, 95:1891-1899

26. Sanduja S, Blanco FF, Young LE, Kaza V, Dixon DA: The role of tristetraprolin in cancer and inflammation. Front Biosci (Landmark Ed) 2012, 17:174-188

27. Tiedje C, Diaz-Muñoz MD, Trulley $P$, Ahlfors $H$, Laaß K, Blackshear PJ, Turner M, Gaestel M: The RNA-binding protein TTP is a global post-transcriptional regulator of feedback control in inflammation. Nucleic Acids Res 2016, 44:7418-7440

28. Stoecklin G, Stubbs T, Kedersha N, Wax S, Rigby WF Blackwell TK, Anderson P: MK2-induced tristetraprolin:14-3-3 complexes prevent stress granule association and ARE-mRNA decay. EMBO J 2004, 23:1313-1324

29. Chrestensen CA, Schroeder MJ, Shabanowitz J, Hunt DF, Pelo JW, Worthington MT, Sturgill TW: MAPKAP kinase 2 phosphorylates tristetraprolin on in vivo sites including Ser178, a site required for 14 3-3 binding. J Biol Chem 2004, 279:10176-10184

30. Brook M, Tchen CR, Santalucia T, McIlrath J, Arthur JS, Saklatvala J, Clark AR: Posttranslational regulation of tristetraprolin subcellular localization and protein stability by p38 mitogen-activated protein kinase and extracellular signal-regulated kinase pathways. Mol Cell Biol 2006, 26:2408-2418

31. Tiedje C, Ronkina N, Tehrani M, Dhamija S, Laass K, Holtmann H, Kotlyarov A, Gaestel M: The p38/MK2-driven exchange between tristetraprolin and $\mathrm{HuR}$ regulates $\mathrm{AU}-$ rich element-dependent translation. PLoS Genet 2012, 8:e1002977

32. Cao H, Dzineku F, Blackshear PJ: Expression and purification of recombinant tristetraprolin that can bind to tumor necrosis factoralpha mRNA and serve as a substrate for mitogen-activated protein kinases. Arch Biochem Biophys 2003, 412:106-120

33. Taylor GA, Carballo E, Lee DM, Lai WS, Thompson MJ, Patel DD, Schenkman DI, Gilkeson GS, Broxmeyer HE, Haynes BF, Blackshear PJ: A pathogenetic role for TNF alpha in the syndrome of cachexia, arthritis, and autoimmunity resulting from tristetraprolin (TTP) deficiency. Immunity 1996, 4:445-454

34. Lafarga V, Cuadrado A, Lopez de Silanes I, Bengoechea R, Fernandez-Capetillo O, Nebreda AR: p38 Mitogen-activated protein 
kinase- and HuR-dependent stabilization of p21(Cip1) mRNA mediates the G(1)/S checkpoint. Mol Cell Biol 2009, 29:4341-4351

35. Abdelmohsen K, Pullmann R Jr, Lal A, Kim HH, Galban S, Yang X, Blethrow JD, Walker M, Shubert J, Gillespie DA, Furneaux H, Gorospe M, Gorospe M: Phosphorylation of HuR by Chk2 regulates SIRT1 expression. Mol Cell 2007, 25:543-557

36. Doller A, Huwiler A, Müller R, Radeke HH, Pfeilschifter J, Eberhardt W: Protein kinase C alpha-dependent phosphorylation of the mRNA-stabilizing factor HuR: implications for posttranscriptional regulation of cyclooxygenase-2. Mol Biol Cell 2007, $18: 2137-2148$

37. Kim HH, Abdelmohsen K, Lal A, Pullmann R Jr, Yang X, Galban S, Srikantan S, Martindale JL, Blethrow J, Shokat KM, Gorospe M, Gorospe M: Nuclear HuR accumulation through phosphorylation by Cdk1. Genes Dev 2008, 22:1804-1815

38. Schichl YM, Resch U, Hofer-Warbinek R, de Martin R: Tristetraprolin impairs NF-kappaB/p65 nuclear translocation. J Biol Chem 2009, 284:29571-29581

39. Kafasla P, Skliris A, Kontoyiannis DL: Post-transcriptional coordination of immunological responses by RNA-binding proteins. Nat Immunol 2014, 15:492-502

40. Schaefer JS, Montufar-Solis D, Klein JR: A role for IL-10 in the transcriptional regulation of Roquin-1. Gene 2014, 549:134-140

41. Matsushita K, Takeuchi O, Standley DM, Kumagai Y, Kawagoe T, Miyake T, Satoh T, Kato H, Tsujimura T, Nakamura H, Akira S: $\mathrm{Zc} 3 \mathrm{~h} 12 \mathrm{a}$ is an RNase essential for controlling immune responses by regulating mRNA decay. Nature 2009, 458:1185-1190

42. Young LE, Sanduja S, Bemis-Standoli K, Pena EA, Price RL, Dixon DA: The mRNA binding proteins HuR and tristetraprolin regulate cyclooxygenase 2 expression during colon carcinogenesis. Gastroenterology 2009, 136:1669-1679

43. Qiu LQ, Stumpo DJ, Blackshear PJ: Myeloid-specific tristetraprolin deficiency in mice results in extreme lipopolysaccharide sensitivity in an otherwise minimal phenotype. J Immunol 2012, 188:5150-5159

44. Chen J, Cascio J, Magee JD, Techasintana P, Gubin MM, Dahm GM, Calaluce R, Yu S, Atasoy U: Posttranscriptional gene regulation of IL-17 by the RNA-binding protein HuR is required for initiation of experimental autoimmune encephalomyelitis. J Immunol 2013, 191: $5441-5450$

45. Katsanou V, Papadaki O, Milatos S, Blackshear PJ, Anderson P, Kollias G, Kontoyiannis DL: HuR as a negative posttranscriptional modulator in inflammation. Mol Cell 2005, 19:777-789

46. Srikantan S, Tominaga K, Gorospe M: Functional interplay between RNA-binding protein HuR and microRNAs. Curr Protein Pept Sci 2012, 13:372-379

47. Kim Y, Noren Hooten N, Dluzen DF, Martindale JL, Gorospe M, Evans MK: Posttranscriptional regulation of the inflammatory marker C-reactive protein by the RNA-binding protein HuR and microRNA 637. Mol Cell Biol 2015, 35:4212-4221

48. Newman R, McHugh J, Turner M: RNA binding proteins as regulators of immune cell biology. Clin Exp Immunol 2016, 183:37-49

49. Hodson DJ, Janas ML, Galloway A, Bell SE, Andrews S, Li CM, Pannell R, Siebel CW, MacDonald HR, De Keersmaecker K, Ferrando AA, Grutz G, Turner M: Deletion of the RNA-binding proteins ZFP36L1 and ZFP36L2 leads to perturbed thymic development and T lymphoblastic leukemia. Nat Immunol 2010, 11: 717-724

50. Papadaki O, Milatos S, Grammenoudi S, Mukherjee N, Keene JD, Kontoyiannis DL: Control of thymic T cell maturation, deletion and egress by the RNA-binding protein HuR. J Immunol 2009, 182: 6779-6788

51. Diaz-Muñoz MD, Bell SE, Fairfax K, Monzon-Casanova E, Cunningham AF, Gonzalez-Porta M, Andrews SR, Bunik VI, Zarnack K, Curk T, Heggermont WA, Heymans S, Gibson GE, Kontoyiannis DL, Ule J, Turner M: The RNA-binding protein HuR is essential for the B cell antibody response. Nat Immunol 2015, 16: $415-425$
52. Phillips K, Kedersha N, Shen L, Blackshear PJ, Anderson P: Arthritis suppressor genes TIA-1 and TTP dampen the expression of tumor necrosis factor alpha, cyclooxygenase 2 , and inflammatory arthritis. Proc Natl Acad Sci U S A 2004, 101:2011-2016

53. Durand S, Abadie P, Angeletti S, Genti-Raimondi S: Identification of multiple differentially expressed messenger RNAs in normal and pathological trophoblast. Placenta 2003, 24:209-218

54. Stumpo DJ, Trempus CS, Tucker CJ, Huang W, Li L, Kluckman K, Bortner DM, Blackshear PJ: Deficiency of the placenta- and yolk sacspecific tristetraprolin family member ZFP36L3 identifies likely mRNA targets and an unexpected link to placental iron metabolism. Development 2016, 143:1424-1433

55. Werno C, Schmid T, Schnitzer SE, Peters K, Milke L, Brüne B: A combination of hypoxia and lipopolysaccharide activates tristetraprolin to destabilize proinflammatory mRNAs such as tumor necrosis factor-alpha. Am J Pathol 2010, 177:1104-1112

56. Stumpo DJ, Byrd NA, Phillips RS, Ghosh S, Maronpot RR, Castranio T, Meyers EN, Mishina Y, Blackshear PJ: Chorioallantoic fusion defects and embryonic lethality resulting from disruption of Zfp36L1, a gene encoding a CCCH tandem zinc finger protein of the Tristetraprolin family. Mol Cell Biol 2004, 24:6445-6455

57. Katsanou V, Milatos S, Yiakouvaki A, Sgantzis N, Kotsoni A, Alexiou M, Harokopos V, Aidinis V, Hemberger M, Kontoyiannis DL: The RNA-binding protein Elavl1/HuR is essential for placental branching morphogenesis and embryonic development. Mol Cell Biol 2009, 29:2762-2776

58. Carrick DM, Blackshear PJ: Comparative expression of tristetraprolin (TTP) family member transcripts in normal human tissues and cancer cell lines. Arch Biochem Biophys 2007, 462:278-285

59. Karipcin FS, Ensari TA, Kayisli UA, Guzel E, Kallen CB, Seli E: The mRNA-binding protein HuR is regulated in the menstrual cycle and repressed in ectopic endometrium. Reprod Sci 2011, 18: $145-155$

60. Ball CB, Rodriguez KF, Stumpo DJ, Ribeiro-Neto F, Korach KS, Blackshear PJ, Birnbaumer L, Ramos SB: The RNA-binding protein, ZFP36L2, influences ovulation and oocyte maturation. PLoS One 2014, 9:e97324

61. Liu X, Li X, Ma R, Xiong B, Sun S-C, Liu H, Gu L: Tristetraprolin functions in cytoskeletal organization during mouse oocyte maturation. Oncotarget 2016, 7:53330-53338

62. Miao YL, Kikuchi K, Sun QY, Schatten H: Oocyte aging: cellular and molecular changes, developmental potential and reversal possibility. Hum Reprod Update 2009, 15:573-585

63. Bianchi E, Barbagallo F, Valeri C, Geremia R, Salustri A, De Felici M, Sette C: Ablation of the Sam68 gene impairs female fertility and gonadotropin-dependent follicle development. Hum Mol Genet 2010, 19:4886-4894

64. Herington JL, Bruner-Tran KL, Lucas JA, Osteen KG: Immune interactions in endometriosis. Expert Rev Clin Immunol 2011, 7: 611-626

65. Smith KA, Pearson CB, Hachey AM, Xia DL, Wachtman LM: Alternative activation of macrophages in rhesus macaques (Macaca mulatta) with endometriosis. Comp Med 2012, 62:303-310

66. Monsanto SP, Edwards AK, Zhou J, Nagarkatti P, Nagarkatti M, Young SL, Lessey BA, Tayade C: Surgical removal of endometriotic lesions alters local and systemic proinflammatory cytokines in endometriosis patients. Fertil Steril 2016, 105:968-977.e5

67. McKinnon BD, Bertschi D, Bersinger NA, Mueller MD: Inflammation and nerve fiber interaction in endometriotic pain. Trends Endocrinol Metab 2015, 26:1-10

68. Fox C, Morin S, Jeong JW, Scott RT, Lessey BA: Local and systemic factors and implantation: what is the evidence? Fertil Steril 2016, 105:873-884

69. Karalok HM, Aydin E, Saglam O, Torun A, Guzeloglu-Kayisli O, Lalioti MD, Kristiansson H, Duke CM, Choe G, Flannery C, Kallen CB, Seli E: mRNA-binding protein TIA-1 reduces cytokine expression in human endometrial stromal cells and is down-regulated 
in ectopic endometrium. J Clin Endocrinol Metab 2014, 99: E2610-E2619

70. Yu CX, Song JH, Liang L: Correlation of changes of (non)exfoliated endometrial organelles and expressions of Musashi- 1 and $\beta$-catenin with endometriosis in menstrual period. Gynecol Endocrinol 2014, 30:861-867

71. Hsiao KY, Wu MH, Chang N, Yang SH, Wu CW, Sun HS, Tsai SJ: Coordination of AUF1 and miR-148a destabilizes DNA methyltransferase $1 \mathrm{mRNA}$ under hypoxia in endometriosis. Mol Hum Reprod 2015, 21:894-904

72. Rai R, Regan L: Recurrent miscarriage. Lancet 2006, 368:601-611

73. Khalaj K, Wessels JM, Kridli RT, Bidarimath M, LaMarre J, Tayade C: mRNA destabilizing factors: tristetraprolin expression at the porcine maternal-fetal interface. Am J Reprod Immunol 2015, 73: 402-416

74. Khalaj K, Luna RL, de França MER, de Oliveira WH, Peixoto CA, Tayade C: RNA binding protein, tristetraprolin in a murine model of recurrent pregnancy loss. Oncotarget 2016, 7:72486-72502

75. Jemal A, Bray F, Center MM, Ferlay J, Ward E, Forman D: Global cancer statistics. CA Cancer J Clin 2011, 61:69-90

76. Moss C, Kaye SB: Ovarian cancer: progress and continuing controversies in management. Eur J Cancer 2002, 38:1701-1707

77. Siegel R, Ma J, Zou Z, Jemal A: Cancer statistics, 2014. CA Cancer J Clin 2014, 64:9-29

78. Bielli $\mathrm{P}$, Busà R, Paronetto MP, Sette C: The RNA-binding protein Sam68 is a multifunctional player in human cancer. Endocr Relat Cancer 2011, 18:R91-R102

79. Dong L, Che H, Li M, Li X: Sam68 is overexpressed in epithelial ovarian cancer and promotes tumor cell proliferation. Med Sci Monit 2016, 22:3248-3256

80. Chen T, Damaj BB, Herrera C, Lasko P, Richard S: Self-association of the single-KH-domain family members Sam68, GRP33, GLD-1, and Qk1: role of the KH domain. Mol Cell Biol 1997, 17:5707-5718

81. Zhang Z, Xu Y, Sun N, Zhang M, Xie J, Jiang Z: High Sam68 expression predicts poor prognosis in non-small cell lung cancer. Clin Transl Oncol 2014, 16:886-891

82. Zhang Z, Yu C, Li Y, Jiang L, Zhou F: Utility of SAM68 in the progression and prognosis for bladder cancer. BMC Cancer 2015, 15:364

83. Wang Y, Liang L, Zhang J, Li M, Zhu J, Gong C, Yang L, Zhu J, Chen L, Ni R: Sam68 promotes cellular proliferation and predicts poor prognosis in esophageal squamous cell carcinoma. Tumour Biol $2015,36: 8735-8745$

84. Liao WT, Liu JL, Wang ZG, Cui YM, Shi L, Li TT, Zhao XH, Chen XT, Ding YQ, Song LB: High expression level and nuclear localization of Sam68 are associated with progression and poor prognosis in colorectal cancer. BMC Gastroenterol 2013, 13:126

85. Zhao X, Li Z, He B, Liu J, Li S, Zhou L, Pan C, Yu Z, Zhao X: Sam68 is a novel marker for aggressive neuroblastoma. Onco Targets Ther 2013, 6:1751-1760

86. Wang Y, Zhang W, Wang X, Wang D, Xie J, Tang C, Xi Q, Zhong J, Deng Y: Expression of Sam68 correlates with cell proliferation and survival in epithelial ovarian cancer. Reprod Sci 2017, 24:97-108

87. Liu K, Li L, Nisson PE, Gruber C, Jessee J, Cohen SN: Neoplastic transformation and tumorigenesis associated with sam68 protein deficiency in cultured murine fibroblasts. J Biol Chem 2000, 275: 40195-40201

88. Wang Q, Li Y, Zhou J, Liu J, Qin J, Xing F, Zhang J, Cheng J: Clinical significance of Sam68 expression in endometrial carcinoma. Tumour Biol 2015, 36:4509-4518

89. Wang H, Ding N, Guo J, Xia J, Ruan Y: Dysregulation of TTP and HuR plays an important role in cancers. Tumour Biol 2016, 37: $14451-14461$

90. Wang D, Wang M, Hu C, Shuang T, Zhou Y, Yan X: Expression of the ELAV-like protein HuR in the cytoplasm is associated with endometrial carcinoma progression. Tumour Biol 2014, 35:11939-11947
91. Davidson B, Holth A, Hellesylt E, Hadar R, Katz B, Tropé CG, Reich R: HUR mRNA expression in ovarian high-grade serous carcinoma effusions is associated with poor survival. Hum Pathol 2016, 48:95-101

92. Yi X, Zhou Y, Zheng W, Chambers SK: HuR expression in the nucleus correlates with high histological grade and poor disease-free survival in ovarian cancer. Aust N Z J Obstet Gynaecol 2009, 49: 93-98

93. Chai Y, Liu J, Zhang Z, Liu L: HuR-regulated lncRNA NEAT1 stability in tumorigenesis and progression of ovarian cancer. Cancer Med 2016, 5:1588-1598

94. Bousquet-Antonelli C, Deragon JM: A comprehensive analysis of the La-motif protein superfamily. RNA 2009, 15:750-764

95. Jackson RJ, Hellen CUT, Pestova TV: The mechanism of eukaryotic translation initiation and principles of its regulation. Nat Rev Mol Cell Biol 2010, 11:113-127

96. Iorio MV, Visone R, Di Leva G, Donati V, Petrocca F, Casalini P, Taccioli C, Volinia S, Liu CG, Alder H, Calin GA, Ménard S, Croce CM: MicroRNA signatures in human ovarian cancer. Cancer Res 2007, 67:8699-8707

97. Iorio MV, Croce CM: MicroRNA dysregulation in cancer: diagnostics, monitoring and therapeutics: a comprehensive review. EMBO Mol Med 2012, 4:143-159

98. Lee Y, Kim M, Han J, Yeom KH, Lee S, Baek SH, Kim VN: MicroRNA genes are transcribed by RNA polymerase II. EMBO J 2004, 23:4051-4060

99. Fuller-Pace FV, Moore HC: RNA helicases p68 and p72: multifunctional proteins with important implications for cancer development. Future Oncol 2011, 7:239-251

100. Trabucchi M, Briata P, Garcia-Mayoral M, Haase AD, Filipowicz W, Ramos A, Gherzi R, Rosenfeld MG: The RNA-binding protein KSRP promotes the biogenesis of a subset of microRNAs. Nature 2009, 459:1010-1014

101. Kawahara Y, Mieda-Sato A: TDP-43 promotes microRNA biogenesis as a component of the Drosha and Dicer complexes. Proc Natl Acad Sci U S A 2012, 109:3347-3352

102. Han C, Liu Y, Wan G, Choi HJ, Zhao L, Ivan C, He X, Sood AK, Zhang X, Lu X: The RNA-binding protein DDX1 promotes primary microRNA maturation and inhibits ovarian tumor progression. Cell Rep 2014, 8:1447-1460

103. Hsu KF, Shen MR, Huang YF, Cheng YM, Lin SH, Chow NH, Cheng SW, Chou CY, Ho CL: Overexpression of the RNA-binding proteins Lin28B and IGF2BP3 (IMP3) is associated with chemoresistance and poor disease outcome in ovarian cancer. Br J Cancer 2015, 113:414-424

104. Navarro G, Pan J, Torchilin VP: Micelle-like nanoparticles as carriers for DNA and siRNA. Mol Pharm 2015, 12:301-313

105. Huang YH, Peng W, Furuuchi N, Gerhart J, Rhodes K, Mukherjee N, Jimbo M, Gonye GE, Brody JR, Getts RC, Sawicki JA: Delivery of therapeutics targeting the mRNA-binding protein HuR using 3DNA nanocarriers suppresses ovarian tumor growth. Cancer Res 2016, 76: $1549-1559$

106. Muralidharan R, Panneerselvam J, Chen A, Zhao YD, Munshi A, Ramesh R: HuR-targeted nanotherapy in combination with AMD3100 suppresses CXCR4 expression, cell growth, migration and invasion in lung cancer. Cancer Gene Ther 2015, 22:581-590

107. Singh JA, Cameron C, Noorbaloochi S, Cullis T, Tucker M, Christensen R, Ghogomu ET, Coyle D, Clifford T, Tugwell P, Wells GA: Risk of serious infection in biological treatment of patients with rheumatoid arthritis: a systematic review and meta-analysis. Lancet 2015, 386:258-265

108. Rosman Z, Shoenfeld Y, Zandman-Goddard G: Biologic therapy for autoimmune diseases: an update. BMC Med 2013, 11:88

109. Patial S, Blackshear PJ: Tristetraprolin as a therapeutic target in inflammatory disease. Trends Pharmacol Sci 2016, 37:811-821 